\title{
CYBORGS, MUJERES Y DEBATES. EL CIBERFEMINISMO COMO TEORÍA CRÍTICA
}

\section{Almudena García Manso*}

\section{RESUMEN}

Este trabajo platea la base de un movimiento, el ciberfeminismo, que está anclado a su propia realidad: Internet, y que intenta sintetizar su significado feminista, basado principalmente en la imagen Cyborg, y el significado que dicho movimiento le da a la realidad, vista a través de Internet, con el fin de transformarla de manera plástica, irónica y política.

\section{PALABRAS CLAVE}

Cyborg, Ciberfeminismo, Internet, Tecnologías, Feminismo.

\begin{abstract}
This document consists of a social movement, the cyberfeminism, based on its own reality: Internet. This movement tries to synthesize its feminist meaning, based on the Cyborg theory, and the meaning that this movement gives the reality, with the purpose of transforming it of artistic, ironic and political way.
\end{abstract}

\section{KEY WORDS}

Cyborg, cyberfeminism, internet, technologies, feminism.

I. No se tiene conocimiento sobre cuánto tiene de realidad social lo que se puede contemplar y lo que puede acontecer en Internet, incluso lo que se esconde tras los hechos virtuales. Aún es más, partiendo del supuesto que Internet viene a ser una proyección de lo social, ésta tiende a ser más un algo que nos muestra los posibles anhelos, fantasías, fantasmas, esperanzas que lo que es como representación de los hechos sociales tal cual.

Hay que insistir en la idea que tiende a ser un mundo que comparte con el arte, la literatura y el cine sus principales referentes. De hecho estos son, hoy por hoy, sus principales referentes.

Si a esto le sumamos que el acceso a gran parte de los contenidos es abierto y universal, conceptos que perfectamente pueden ser matizados por la sombra de la alterglobalización, el meta capitalismo acelerado y el feroz consumo que caracterizan a la mayor parte de las acciones en Internet, es por ello por lo que no

\footnotetext{
* Profesora Escuela Politécnica Superior. Ingenierías TIC. Universidad Alfonso X El Sabio y miembro de la ACMS
} 
hay que desdeñar la idea que en este trabajo se analiza, fundamentalmente la idea de representación femenina, claramente conceptualizada en ideologías y comportamientos que superan con mucho lo que ocurre en Internet y que, como ha de suceder con el arte o la literatura, son en general instrumentos amplificadores de elementos claramente sociales.

En definitiva, Internet no es más que una esfera de consumo en estado puro, incluso de las ideas que intentan transformar la realidad que va más allá de las propias máquinas. Las palabras y las imágenes, en este sentido, sólo tienen razón en el acto del consumo, el cual se convierte en una acción y a la vez en un contexto: Una suerte de actitud ante el mundo. Y, así, las ciberfeministas buscaron un nuevo camino a un feminismo que parecía estancado y que en la red se había convertido en planteamiento dominado por la lógica de la dominación masculina de la tecnología, dando lugar a un recrudecimiento de las posiciones masculinas más clásicas, basadas en el dominio de las palabras de las mujeres y, sobre todo, de sus cuerpos, dejándolas un espacio de feminidad que políticamente (así como en lo social y lo económico) las relegaba a un plano tradicional de marginalidad. El ciberfeminismo busca la ruptura de todo esto en un ejercicio de romper con el "devenir" mujer para convertirlo en un "deseo" de ser máquinas: cyborgs. Todo ello planteado de manera muy teórica, general y preliminar, con la intención de querer, de poder, llegar a ver una etnografía hecha por las máquinas, no por un anhelo de objetividad, sino por sabernos que estamos compartiendo un futuro diferente.

El término ciberfeminismo fluye en el ciberespacio sin materializarse en una definición unívoca, libremente navega en busca de un cuerpo que lo sustente, aunque quizás la ausencia de definición le proporciona carácter de cuerpo, un cuerpo polimórfico. Este hecho indefinido del término parece convenir a ciertos colectivos ciberfeministas, puesto que la inmaterialidad aporta cierto aire antijerárquico que desemboca a su vez en tácticas a-identidad, lo que confiere libertad para poder adoptar cualquier faceta.

Es por ello por lo que Faith Wilding apremia por definir los objetivos del ciberfeminismo para poder llegar a ser eficaces en su lucha (Wilding, 1998). Para conocer detalladamente cuales son los objetivos, su lucha, su filosofía y teoría, con el fin de poder llegar a realizar un enunciado o varios ciberfeministas, se tiene que realizar un repaso histórico desde sus inicios, entendiendo así los motivos que dieron origen al movimiento. Esta trayectoria histórica nos permitirá comprender o entender las dos ramas generales de actuación claramente diferenciadas en lo que ha derivado el ciberfeminismo.

La corriente ciberfeminista surge de manera espontánea a principio de la década de los años 90 a raíz de un documento elaborado por Donna Haraway (Estados Unidos), denominado A Cyborg Manifesto: Science, Technology and Socialist-Feminism in the Late Twenty Century, referenciado de forma sintética como Manifiesto Cyborg, que fue curiosamente glosado por el grupo VNS Matrix (Australia), en la forma que luego veremos, dando origen al primer manifiesto 
ciberfeminista. Posteriormente, en 1996, Sadie Plant publica el libro Zeros + Ones. Digital Women + The New Technoculture, donde muestra la alianza y complicidad histórica entre mujer y tecnología. En septiembre de 1997 se celebró el Primer Encuentro Internacional Ciberfeminista, dentro de la Documenta X, un congreso internacional de arte contemporáneo, realizado en Kassel (Alemania); en marzo de 1999 tuvo lugar el segundo congreso ciberfeminista, en Rotterdam (Holanda) y el tercero, y último hasta la fecha, en diciembre de 2001 en Hamburgo (Alemania).

El Manifiesto Cyborg de Haraway es una búsqueda de un nuevo feminismo socialista capaz de luchar contra lo que denomina la informática de la dominación, un nuevo espacio creado por la tecnología, ambivalente, fluido y contradictorio, donde se pierde la referencia, la identidad. La llamada "informática de dominación (masculina)" no afecta por igual a todos y las mujeres, como parte de los grupos desprotegidos, que es su principal dominio. Y si la cultura occidental se ha construido sobre dualismos referenciales: yo/otro, mente/cuerpo, cultura/naturaleza, hombre/mujer, civilizado/primitivo, realidad/apariencia, todo/parte, agente/ recurso, constructor/construido, activo/pasivo, bien/mal, verdad/ilusión, total/parcial. Dios/hombre, etc., las nuevas tecnologías tienden a romper dichos dualismos: ya no se distingue lo natural de lo artificial, le mente del cuerpo o la naturaleza de lo cibernético. El cuerpo pierde sus límites, se difuminan en un maridaje tecnobiológico. Así nace el cyborg, mitad máquina, mitad humano, como paradigma de la lucha contra la informática de la dominación: El cyborg es una criatura en un mundo postgenérico. En particular, el "cyborg" acaba con la supuesta naturaleza femenina, unificadora de identidades y dictadora de biografías. El sexo deja de ser el tirano del cuerpo: "Los cyborgs pueden considerar más seriamente el aspecto parcial, fluido del sexo y de la encarnación sexual. El género, después de todo, podría no ser la identidad global, incluso si tiene anchura y calado histórico" (Haraway, 1991: 180). Las tecnologías han creado una informática de la dominación y, a la vez, han creado los cyborgs. Según Haraway, debemos alejarnos de toda tecnofobia y aceptar la unión cuerpo-máquina como una extensión del cuerpo, de nuestras vidas y de nuestra intimidad. El ciberfeminismo piensa que sólo así podremos desterrar la sumisión dominativa de la informática.

En el verano de 1991, el mismo año de publicación del Manifiesto Cyborg de Haraway, cuatro artistas australianas crean el Cyberfeminist Manifesto for the 21st Century. El grupo VNS Matrix, (VeNuS Matrix), formado por Josephine Starrs, Julianne Pierce, Francesca Da Rimini y Virginia Barrat, tiene su origen en Adelaide (Australia), resultando ser el complemento guerrero y subversivo radical a los planteamientos teóricos de Haraway. VNS Matrix instaura estrategias de lucha feministas tales como "la ironía y la inversión de estereotipos culturales, como método para abordar algunas de las problemáticas esenciales en torno a la relación entre mujer y tecnología: acceso, educación, trabajo, imagen de las chicas/nenas/mujeres en la cultura y los videojuegos populares, etc." (Galloway, 1996). Nacen, por lo tanto, como "el virus" ciberfeminista que contagiará el sistema 
antropocéntrico tecnológico.

La inclusión gráfica del manifiesto ciberfeminista resalta su carácter artístico, que juega con la doble idea de representación e impresión, un juego de iconos ideológicos, de ambigüedades que abren paso a miradas más belicosas, revolucionarias y alternativas. No sólo es un manifiesto, en el sentido de un texto escrito, con un sentido y una intención, sino que, además, está diseñado para transmitir más de lo que transmite el texto, y para resaltar cierto contenido del mismo. Es un mensaje textual y, a la vez, visual. Tal hecho provoca una corriente de actuación del ciberfeminismo que centra su actividad en la edición artística, que posteriormente, en 1996, da lugar a que el grupo VNS Matrix realizara el Bitch Mutant Manifesto, como continuación de un lenguaje artístico provocador y reivindicativo, que basa su acción en la corrosión de pensamiento. En el nuevo manifiesto ya se apuntan los fundamentos teóricos del ciberfeminismo, tales como identidad fluida y ausencia de género, envueltos en un lenguaje barroco postmodernista y tecnológico: "Applets primorosos engalanan mi garganta. Soy una cadena binaria. Soy puro artificio. Lee mi memoria de sólo lectura. Cárgame en tu imaginación pornográfica. Escríbeme. La identidad se descomprime polimorfa y se infiltra en el sistema desde la raíz."; «...pero en el ciberespacio no hay fronteras /Pero en el espiralespacio no hay ellos /sólo hay *nosotros*...»", y salpicado con píldoras provocativas: "chúpame el código" (Da Rimini, 1996).

Por su parte, Sadie Plant, en su libro "Ceros + Unos. Mujeres digitales + la nueva Tecnocultura", ahonda en un pasado de la tecnología que es femenino, pero no feminista. Máquina/ordenador/red y mujer comparten similitudes miméticas en cuanto a flexibilidad, fluidez y plenipotencialidad, lo que hace que surja una alianza entre máquinas y mujeres. Plant actualiza la figura olvidad de Ada Lovelace, creadora, con unas notas al margen en una biografía traducida por ella, de la Máquina Analítica, precursora, a su vez, de los ordenadores actuales. Ada Lovelace llevó una vida secundaria, oculta, siempre referenciada a otros (a su padre Lord Byron y a Charles Babbage) y que fue la creadora de la Máquina de Diferencias y posteriormente de la Máquina Analítica. Viviendo bajo la sombra/acusación de histérica (de matriz movida), le administraban láudano como solución a sus supuestos males, por otra parte, tuvo que renunciar a su visión tecnológica para casarse supuestamente por amor con un hombre al que describió como "mi mascota preferida" y por el cual no sentía ninguna inclinación, por otro lado, tampoco tuvo hijos con los que sentir el supuesto instinto maternal (Plant, 1997: 34). Plant, tomando como referencia a Ada, denuncia el papel secundario que siempre ha tenido la mujer en la tecnología: a la sombra de grandes investigadores: "él organizaba, ella operaba, él mandaba, ella servía, él hacía grandes descubrimientos, ella se ocupaba de las notas al pie de página. [...] Ella hacía los trabajos que él consideraba mundanos" (Plant, 1997: 41), o como usuaria de la misma, o como telefonista, o como mecanógrafa, o como secretaria. Relaciona los géneros masculino/femenino con los 1 y 0 informáticos, dentro de los dualismos perfectos 
que han representado la cultura occidental hasta la fecha: "Los ceros y los unos del código máquina parecen proponerse como símbolos perfectos de los órdenes de la realidad occidental, las antiguas categorías lógicas que establecían las diferencia entre apagado y encendido, derecha e izquierda [...] mente y cuerpo [...]. Y cuando llegan al sexo, forman una linda pareja. Hombre y mujer, macho y hembra, masculino y femenino. Uno y cero parecían correctos, hechos el uno para el otro: 1, la línea definida y vertical, y 0 , el diagrama de nada en absoluto; pene y vagina" (Plant, 1997: 40). Sin embargo, esta estructura perfecta se quiebra con la llegada de Internet. Se pierde el centro de referencia, el orden establecido, la jerarquía; no hay dualismos, norte y sur, arriba y abajo; todo es relacional, en un mismo plano o en infinitos. La red guarda una cierta relación con los telares antiguos, donde las mujeres manejaban la lanzadera tejiendo la red a su deseo. Existe una simpatía entre máquina y mujer por la capacidad que tienen ambas de ser cualquier cosa, de ser según lo que hacen (algo parecido a lo que ocurre con un telar tradicional). Simpatía que alcanza su máximo exponente en la máquina de Turing de principios del siglo $\mathrm{XX}$, creada para demostrar la integridad, consistencia y resolubilidad de las matemáticas según los problemas planteados por Hilbert, demostrando que las matemáticas son capaces de resolver cualquier problema. La máquina de Turing es una especie de máquina universal, que funciona como otra máquina según el código que tenga. La máquina de Turing echó por tierra la trascendencia de las matemáticas, dejando claro que habría problemas irresolubles con independencia del avance tecnológico: se perdía un nuevo punto de apoyo y Plant sitúa una similitud perversa entre la máquina de Turing, plenipotencial, y la mujer. El mismo libro de Plant es una red, un conjunto de enlaces que van y vienen, tejiendo una historia sobre la tecnología y la mujer, sobre su histórica relación, sus hitos relevantes en el siglo XX protagonizados por mujeres, sobre el futuro cyborg, la ausencia de sexos o la multiplicidad de los mismos, sobre la pérdida definitiva de los dualismos con la lógica cuántica, donde se es y no se es a la vez; resultando un tapiz que resalta la alianza escondida que ha existido siempre entre máquina y mujer y la sitúa como fundamento para sinergias futuras feministas.

II. La ausencia de definición (o, en su defecto, el hacerlo vía antitesis, OBN, 1997) es explotada por algunas ciberfeministas como ejemplo de la fluidez que caracteriza su movimiento, de su capacidad para adaptarse y serlo todo, sin llegar a ser completo, y de su rebeldía a ser encasilladas, homogeneizadas. Tal y como indica Rosie X en la revista ciberfeminista on-line GeekGirl: "incluso la idea de un «movimiento en sí» está basado en un viejo estilo feminista retórico que tiende a homogeneizar a todas las mujeres en el mismo quieres/necesitas/deseas" (Kuni, 1998). Sin embargo, otras ciberfeministas abogan por una definición clara del término que ayude a una lucha eficaz, para que deje de ser una "decepción" y aporte una "línea política viable" y no "sólo un espíritu sindicalista" (Galloway, 1996). De manera genérica, Susan Hawthorne y Renate Klein proponen resaltar las diferencias 
entre géneros que existen en las nuevas tecnologías, dirigiendo el ciberfeminismo a su eliminación: "Ciberfeminismo es una filosofía que reconoce, en primer lugar, que hay diferencias en energía entre las mujeres y los hombres, específicamente en el discurso digital; y en segundo lugar, ese ciberfeminismo desea cambiar esa situación" (Hawthorne; Klein, 1999: 2). Las diferencias que provocan las TICs están encaminadas a ayudar a la mujer, en virtud del carácter femenino que tiene la tecnología, y gracias a la "alianza" entre las máquinas y las mujeres: "el ciberfeminismo para mí implica que se está desarrollando una alianza entre mujeres, máquinas y la nueva tecnología que las mujeres están usando" (Galloway, 1996).

Rosi Braidotti especifica con algo más de detalle, y en un estilo particularmente reivindicativo y guerrero, contra qué tiene que luchar esa alianza entre tecnología y mujeres: "La estrategia más efectiva para las mujeres sigue siendo utilizar la tecnología para liberar nuestra imaginación colectiva del falo y sus valores accesorios, como son el dinero, la exclusión y la dominación, el nacionalismo, la feminidad y la violencia sistematizada" (Braidotti, 1996). En efecto, la idea ciberfeminista de Braidotti se encamina hacia la "imaginación", la cual se debe "liberar" hacia el simbolismo, hacia la creatividad y el arte, fundamentos de su feminismo "diferente". En esta misma línea, Faith Wilding amplía el espectro del ciberfeminismo. Partiendo de que hay varios a la vez, no lo reduce al arte, ni tampoco lo enmarca sólo a lo que parecería que fuera su ámbito natural: el ciberespacio - que es sólo una pequeña parte-, ya que lo verdaderamente importante son los dominios donde se crean las nuevas tecnologías, lo que ella denomina la cyber-life. Espacios e instituciones que está poblados y dominados por hombres y por mentalidades masculinas, en los cuales resulta difícil que entre la mujer o, mejor dicho, el feminismo. Porque, como ella indica, "los elementos de estratificación social pancapitalista están reflejados y reproducidos en el ciberespacio" (Wilding; Cae, 1998).

Es decir, el ciberespacio no está libre de contaminación, no es un espacio neutro, porque sobre él actúan otros dominios, que son los ocupados por los hombres. Por ello se esfuerza en ampliar al máximo el horizonte del ciberfeminismo: "el territorio del ciberfeminismo es amplio. Incluye el espacio objetivo del ciberespacio, instituciones de diseño industrial e instituciones de educación -territorios en los que el proceso tecnológico es clasificado generizadamente de una forma que excluye a la mujer el acceso a los puntos de poder de la tecnocultura" (Wilding; Cae, 1998). Finalmente cabe una definición, un deseo en el sentido de Deleuze, de unir tanto la acción política que plantea Wilding, como la más artística de Braidotti. En este sentido, Verena Kuni aboga por pensar y definir una acción que conjugue teoría y estética ciberfeminista, si bien ella lo reduce al ámbito de Internet, por las posibilidades visuales y de representación que tiene dicho medio. Kuni critica seriamente el estilo anticuado que manifiestan muchas páginas feministas de Internet: páginas con fondos rosas, o floreados y con 
nombres grandilocuentes, históricos o mitológicos, relacionados con entidades, mitos o reinas famosas. Antes bien, aboga, en el mismo estilo que Braidotti, por la ironía, la simulación y la parodia como nuevas formas de representación ciberfeministas: "Me gustaría definir la práctica del ciberfeminismo tanto como una estrategia política como estética; y me gustaría añadir: una estrategia que trabaje concienzudamente con los medios de replicación y simulación, más que referirse a las tradicionales estrategias de representación" (Kuni, 1998).

III. El Manifiesto Cyborg de Donna Haraway imagina una ficción que defiende como real, dado que las fronteras entre la ciencia ficción y las representaciones de la realidad social son una ilusión óptica. Defiende una ficción blasfémica del Cyborg, como revulsivo a la conciencia acomodada occidental, a la tradición secular religiosa, al feminismo socialista y al marxismo, así como una prolongación necesaria del postmodernismo. Un cyborg es un organismo cibernético, un híbrido de máquina y organismo, una criatura de realidad social y también de ficción, es el nuevo eje central de un mundo que ya no depende del género, que no tiene un origen, en el sentido típico occidental de unidad de la cual se dividen el resto de seres, y que, quizá, tampoco tenga fin. El mundo cyborg nace como consecuencia de tres tendencias dentro de la investigación científica de fin de siglo XX: la frontera entre lo humano y lo animal tiende a difuminarse, los últimos avances en biología y teoría evolucionista han adelgazado la línea que separa a los humanos de los animales, volviendo, o intentando volver, a la unidad de naturalezacultura y cuya ruptura es un signo más del dominio antropocéntrico. De igual forma, la frontera entre organismos (animales o humanos) y máquinas, entre lo natural y lo artificial, es también estrecha, haciendo que lo artificial ya sea autónomo, que puede decidir por sí mismo, en definitiva, con el sueño reproductivo del hombre occidental blanco que ya no puede controlar. Y, por último, finalmente, y como consecuencia de lo anterior, los límites entre lo físico y lo no material se hacen imprecisos, la máquina moderna es microelectrónica, es decir, pequeña, casi invisible y por ello ubicua, está hecha de "rayos de sol" (son éter, quintaesencia), al límite, no son más que un fragmento de espectro electromagnético. Este cuadro dibuja un futuro, que para unos es un combate contra aquellos que hoy están seguros en la dominación, en la relativización y apropiación masculinista de cuerpos y sexos, y para otros (los dominados) representa un futuro abierto a múltiples posibilidades.

Desde un punto de vista teórico, Donna Haraway busca una epistemología y una política encaminadas a la unidad, sin ser totalista, y al margen de una supuesta naturaleza femenina. Rompe con el feminismo existencialista y parte de las corrientes ideológicas de los 70, para lo cual afirma que no existe nada en el hecho de ser "mujer" que una de manera natural a las mujeres, tan solo afinidades políticas basadas en lo que denomina "conciencias opositivas". Además, la nueva teoría debe buscar una "unidad política para afrontar con eficacia las dominaciones de «raza», 
«género», «sexualidad» y «clase»» (Haraway, 1991: 157), pero que a la vez no sea totalizadora, que permita las diferencias, las contradicciones y que sea fiel al feminismo socialista. Bajo la perspectiva de Haraway, el feminismo socialista y el feminismo radical han fallado en tal intento. El feminismo socialista alcanza la unidad, no de forma natural, sino en las relaciones de trabajo y sociales. El feminismo radical se basa en una esencialización de la mujer basada en el deseo sexual del hombre, de tal forma que su origen se encuentra en el deseo "del otro". $\mathrm{Su}$ existencia es una no-existencia, al tener su esencia en un deseo ajeno. Reducir a la mujer al puro deseo sexual del hombre borra toda diferencia, lo que la convierte en totalista. La solución a su sistema epistemológico la encuentra en el cyborg: "las feministas del cyborg tienen que decir que 'nosotras' no queremos más matriz natural de unidad y que ninguna construcción es total" (Haraway, 1991: 157). Para construir tal teoría, Haraway dibuja un cuadro dicotómico donde muestra la evolución sufrida desde paradigmas de una sociedad orgánica e industrial hacia otra reajustada por la ciencia y la tecnología. Así, hemos pasado de unas "dominaciones jerárquicas", cómodas, por conocidas, a las nuevas redes que ella denomina "informática de la dominación":

Representación / Simulación; Organismo / Componente biótico; Fisiología / Ingeniería de las comunicaciones; Perfección / Optimización; Reproducción / Réplica exacta; Sexo / Ingeniería genética; Mente / Inteligencia artificial; Patriarcado capitalista blanco / Informática de la dominación.

En efecto, la naturaleza ha desaparecido, lo cual encamina hacia la epistemología que Haraway busca. La ciencia y la tecnología han despojado de toda propiedad esencial a los nuevos objetos, para aplicarles propiedades "de diseño, de dificultades limítrofes, de tasas de movimiento, de lógicas de sistema, de costo de disminución de las dificultades" (Haraway, 1991: 162). Todo se pude montar y desmontar si se dispone del protocolo adecuado, de la codificación adecuada. La naturaleza humana ha perdido tal condición y somos, o seremos, simplemente conceptos probabilísticos $\mathrm{y}$, consecuentemente, la reproducción sexual es sólo una estrategia más de perpetuación, planificada. Dentro de la teoría feminista, lo que importa de la tabla anterior es que el discurso dualista tradicional de mente/cuerpo, animal/humano, organismo / máquina, público / privado, naturaleza / cultura, hombres / mujeres, primitivo / civilizado desaparece por acción de la ciencia y la tecnología: ha sido "tecnodigerido". Es dentro de este marco y con dichos condicionantes donde se deben redefinir las políticas feministas socialistas. Marco que Haraway denomina "relaciones sociales de ciencia y tecnología", indicando que la tecnología no sigue un camino determinista, sino según unas relaciones estructuradas de la sociedad, y que además "la ciencia y la tecnología suministran fuentes frescas de poder, $\mathrm{y}$, por tanto, necesitamos fuentes frescas de análisis y acción política" (Haraway, 1991: 165). Esta nueva redefinición del feminismo, desde una posición socialista, debe partir del cyborg, que es una suerte de yo personal, postmoderno y colectivo, desmontado y vuelto a montar: es el yo que las 
feministas deben codificar. Para ello, para la codificación de dicho "yo" (del entramado cuerpos), cuentan con las tecnologías de las comunicaciones y las biotecnologías, que reducen todo a la fluidez, a la transmisión de la información. En consecuencia, Haraway traslada la codificación a la cibernética, al control y retroalimentación de los sistemas. Dentro de la biotecnología, el problema de la codificación se traslada a la ingeniería genética: los organismos se codifican y se convierten en procesadores de información. Ambas tecnologías, base del cyborg, dependen de la microelectrónica, es decir, de lo invisible y de lo ubicuo, en virtud de lo cual la diferencia entre lo humano y lo cibernético, el cuerpo y la herramienta, se difumina.

Si bien las nuevas tecnologías de la comunicación y la biotecnología llevan al cyborg, como paradigma de la nueva codificación del cuerpo humano, son esas mismas tecnologías las que están transformando la reproducción, la sexualidad, la cultura, el consumo y la producción en lo que Haraway denomina, junto a Richard Gordon, la "economía del trabajo casero", transformación que no afecta por igual a todas los géneros, grupos y etnias. Evidentemente, es en el ámbito doméstico donde más se han introducido las nuevas tecnologías. Desde los años 50 del siglo XX el ámbito casa se tecnificó proponiendo nuevas tareas a las mujeres que, definitivamente, por lo vulnerable de las posiciones, se han montado y desmontado según convenga como recurso ideológico o como fuerza de trabajo en reserva. Las consecuencias para la mujer de la nueva industrialización, creada por las nuevas tecnologías, hacen que sus vidas estén estructuradas en base a sus empleos, precarios y asfixiantes. Precarios, no tanto por la inestabilidad del mismo, sino por la dependencia extrema a él, debido a que puede que sea el único salario familiar. Y asfixiantes por su horario intensivo, que transforma en quimera decimonónica la jornada laboral de cuarenta horas semanales. Ello repercute en su sexualidad, en la reproducción, en la continua necesidad de negociación respecto al cuidado de hijos o padres, en la lejanía respecto a su comunidad, en la soledad y en la vulnerabilidad a envejecer.

Dichas tecnologías afectan a las mujeres en los términos que indica Haraway, y no les son ajenas. Las mismas ciberfeministas, en mayor o menor medida, pertenecen a grupos de élite técnica o científica, incluso a grupos de poder, que desarrollan tales tecnologías y dictan su aplicación. El nuevo feminismo, según Haraway, debería dirigirse a las mujeres que ocupan las posiciones laborales privilegiadas, principalmente en la tecnología y en la producción científica. Una política que debe huir del totalitarismo, de la explicación completa, lo cual no es más que una forma de dominación y de imperialismo. El nuevo feminismo debe estar adaptado al entorno ambivalente, fluido, mixto y contradictorio de la informática de la dominación. Un entorno donde no tienen sentido las dualidades, sino las relaciones entrelazadas de las redes. Haraway describe una pintura de la mujer dentro de la informática de la dominación, destacando una serie de espacios (hogar, mercado, puesto de trabajo remunerado, estado, escuela, clínica-hospital e 
iglesia) donde la clave está precisamente en la ausencia de "lugar", de un espacio de identificación de un yo unitario. Antes al contrario, lo remarcable es la ambivalencia, la multiplicidad de valores y las contradicciones: "la consecuencia es la dispersión; La tarea es sobrevivir en la diáspora" (Haraway, 1991: 170), todo ello es especialmente visible en ciertos espacios de contradicción:

- Hogar: hogares con cabezas de familia femenino; ancianas solas; trabajo casero pagado; resurgimiento de las fábricas domésticas donde se explota al obrero.

- $\quad$ Mercado: continuo consumo como parte de un trabajo por parte de las mujeres, a las que se les destina, para que la compren la profusión de nuevos productos de las nuevas tecnologías; importancia creciente de los mercados informales en el trabajo y bienes de consumo paralelos a las estructuras opulentas de los mercados de la alta tecnología; sistemas de vigilancia a través de transferencias de fondos electrónicos; sexualización intensificada del consumo abstracto y alienado.

- $\quad$ Puesto de trabajo remunerado: continua e intensa división sexual y racial del trabajo, pero crecimiento considerable del número de miembros en categorías de trabajo privilegiado para muchas mujeres blancas y gentes de color; puesta en marcha de modificaciones de horario laboral para facilitar la economía del trabajo casero; trabajo casero y paro; la mayoría de los empleos "marginales" o "feminizados".

- $\quad$ Estado: erosión continuada del estado del bienestar; nacionalidad a través de telemáticas; aumento de la privatización de la vida y de la cultura materiales e ideológicas.

- $\quad$ Escuela: educación buscando la ignorancia de las masas y la represión dentro de la cultura tecnocrática y militarizada; numerosas élites de educación privilegiada en una sociedad progresivamente bimodal.

- Clínica-hospital: relaciones intensificadas entre máquina y cuerpo; aparición de enfermedades nuevas e históricamente específicas; luchas a propósito de los significados y de los medios sanitarios en ambientes saturados de productos y procesos de alta tecnología; feminización continua del trabajo sanitario.

- Iglesia: predicadores fundamentalistas electrónicos "supersalvadores" solemnizando la unión del capital electrónico con los dioses fetiches automatizados; importancia cada vez mayor de las iglesias que se oponen al estado militarizado.

Ante este panorama de contradicciones, la única aseveración totalitaria que se puede entresacar es que la informática de la dominación, el modelo que actualmente impera (basado, a su vez, en la lógica de la dominación masculina), es como una intensificación masiva de la inseguridad y un empobrecimiento cultural, que afecta sobre todo a los más vulnerables y marginados. Éste es el entorno de trabajo de este nuevo feminismo, que además establece, no sólo su espacio, sino sus herramientas. De la misma forma que la informática de la dominación no establece puntos de referencia, tan sólo nodos de comunicación, de mallas relacionales, así el feminismo, de una clara orientación "socialista", debe huir de encontrar el sueño de 
un lenguaje común, de una clasificación taxonómica y de una epistemología política sólida y unificadora. La solución radica en entender la sutileza de las relaciones emergentes, los hilos de seda que tejen las nuevas redes: la naturaleza cyborg, a la fusión de máquinas, animales y humanos para llegar a ser un no-Hombre y quizá entender tales relaciones.

La tecnología presenta en sí una naturaleza ambivalente: representa el discurso antropocéntrico más severo que alimenta la fuerza militar, la dominación, la destrucción, la codificación de cuerpos en forma de los otros. A la vez, el fundamento del género cyborg, parafraseando a Haraway, es llamar a una codificación de la comunicación y la inteligencia para subvertir el mando y el control. La tecnología cyborg rompe cualquier tipo de dualismo perfecto en los que se ha basado la cultura occidental. Difumina las barreras de lo humano y lo tecnológico, del cuerpo y del cerebro electrónico. Acaba con los puntos de referencia, con el yo, con la perfección epistemológica y se regocija en lo imperfecto e inacabado, en la unión ilegítima del humano-máquina, en el ruido. El género cyborg es el fin de la reproducción, para pasar a la regeneración. El género no vendrá impuesto como herencia natural, ya no dictará la biografía ni será metáfora de vida. El género cyborg diluye el sexo en la complejidad fluida de las redes y deja de ser la identidad de referencia, la explicación totalitaria de la vida. Los futuros cyborgs, nacidos de la informática de la dominación, son la esperanza contra la misma: el hijo que devore al padre, en un paradigma a-cronológico, arranque de un nuevo tiempo. Hablando de dioses subversivos, de blasfemias, con las que arranca el manifiesto, Haraway prefiere "ser un cyborg antes que una diosa" (Haraway, 1991: 181).

IV. Tal y como hemos visto, el origen del ciberfeminismo tiene su raíz en el mítico Manifiesto Cyborg de Donna Haraway, el cual fue glosado artísticamente por VNS Matrix. Este hecho ha supuesto la evolución de un ciberfeminismo que sitúa su actividad en el arte. Una parte de dicho ciberfeminismo se centra en el arte del cuerpo, y es denominado Cyberfeminist Body Art. Toma como referencia el Manifiesto Cyborg de Donna Haraway, que, como veremos, aboga por el "espéculo tecnológico adecuado que devuelva el dominio del cuerpo a la mujer" (Haraway, 1991: 169) y también las proclamas de VNS Martrix, tantas veces citadas, de "somos el coño del futuro" y "el clítoris es una línea recta hacia la matriz". De esta forma, el Body Art quiere, dicen sus promotoras, exorcizar el cuerpo femenino convertido en esencia, mediante un complejo trabajo de revalorización y reconstrucción. En este sentido se enmarcan las propias obras de VNS Matrix; Eva Grubinger, con su obra interactiva Netzbiquini, que representa la venta de un bikini cosido con material de red, del cual se pide que se envíen fotos con él puesto (Grubinger, 1995); Nancy Paterson, con Stock Market Skirt, composición formada por una falda conectada a un ordenador, que sube o baja el bajo de la misma, según sube o baja la bolsa (Paterson, 1998); o la obra digital e interactiva Cyberflesh 
Girlmonster de Linda Dement, constituida por una serie de montajes fotográficos de distintas partes del cuerpo femenino, ensamblados de tal forma que semejan creaciones monstruosas (Dement, 1995). Con todo ello, se busca recuperar el cuerpo de la mujer para la mujer; un cuerpo que ha sido poseído de múltiples formas y definido por la cultura del patriarcado. Se pretende mostrar el cuerpo femenino, de forma radical y contestataria, alejándolo de los estereotipos pornográficos o fantasiosos antropocéntricos.

En línea similar al Cyberfeminist Body Art, en lo que se refiere a lucha estéticamente subversiva, ácida y provocadora, que emplea el arte en sus múltiples facetas, se encuentra el llamado Cybergrrl-ism. En dicho movimiento se agrupan las llamadas Webgrrrl, Riotgrrl, Guerrila Girl, Bad Grrl, Plantegrrl, Geekgrrl, etc., que transmiten la idea de que las mujeres han dejado de una vez para siempre la imagen femenina atribuida falsamente, para afirmar que las mujeres están en guerra, que no son pacifistas, sino guerrilleras, chicas disturbio (riot), que son chicas malas, enfadadas, tal y como indica su sufijo onomatopéyico de cólera violenta (-grrl), y que emplean la ironía, la parodia, para expresar sus tesis agresivas: "¡nosotras no estamos en pelotas (naked), esperando a tener un chat caliente contigo!" (Kuni, 1998). Este tipo de movimiento se ve reforzado por ciertas feministas en mayor o menor medida, y denostado por otras en la misma medida. En este sentido, Rosi Braidotti apoya con rotundidad tales movimientos y el empleo de la ironía y la parodia en su artículo $A$ diferent Cyberfeminism. Según ella, los "espíritus creativos tienen ventaja frente a los maestros del metadiscurso" y hoy en día "la filosofía queda rezagada detrás del arte y la ficción" (Braidotti, 1996). Verena Kuni también apoya la replicación, simulación, ironía y parodia como medios de representación feminista, tal y como hemos visto. En dirección contraria se encuentran movimientos feministas como las Old Boys Network (OBD, promotoras del primer congreso ciberfeminista de 1997, antes comentado). Así, Faith Wilding afirma que representan una especie de "anti-teoría" y cuya actividad "no puede reemplazar el trabajo serio que es necesario para identificar y cambiar las estructuras y contenidos de género y el impacto de las nuevas tecnologías en las mujeres a escala mundial" (Wilding, 1998). Incluso Sonia Reverter-Bañón, al indicar que su "actitud estéticamente subversiva se lleva a cabo de manera tan acrítica, y con una falta tan patente de horizonte político, que a menudo está lejos de desestabilizar cualquier esteriotipo" (Reverter-Bañón, 2000). En efecto, como se observa, el ciberfeminismo, a pesar de contar con poco más de una década de existencia, tiene una riqueza sustancial que permite estudios muchos más amplios.

Existen "diferencias en energía entre las mujeres y los hombres, específicamente en el discurso digital". Pero Internet, el ciberespacio, es sólo una parte de dicho discurso digital. Es un fragmento de nueva tecnología que vemos diariamente y a la que de alguna manera podemos acceder, y por ello lo utilizamos cómo única herramienta de trabajo para nuestras luchas. De hecho, las expectativas es que sea un espacio libre de las constricciones de género, al margen del poder 
antropocéntrico, del ansia de dominación.

Así, pues, no podemos reducir el ciberfeminismo a Internet, como tampoco podemos reducirlo a la teoría cyborg. Puede decirse que las VNS Matrix hicieron un flaco favor al Manifiesto de Donna Haraway, glosándolo artísticamente con su Manifiesto Cyberfeminista, porque desviaron la atención hacia lo secundario del Manifiesto. Bien es verdad que Haraway se centra en su mito de "cyborg" como salvación para el nuevo ciberfeminismo socialista, pero no es menos verdad que Haraway denuncia otras muchas situaciones amenazadoras para la mujer, como hemos visto, sobre las cuales no se hace incidencia. Haraway habla de la "informática de la dominación", de la "feminización" del trabajo, de lo vulnerable que se está volviendo la situación de la mujer en virtud de las nuevas tecnologías, de la ruptura de paradigmas dicotómicos, de la ausencia de un "topos" para la mujer dentro del circuito integrado, de cómo todo ello está afectando a su sexualidad, a su reproducción, a su vida privada y social. Haraway pide la construcción de un ciberfeminismo socialista que luche contra todo ello. Las VNS Matrix desviaron la atención hacia lo exótico, hacia el cyborg, consiguiendo que cuando se hable de ciberfeminismo tan sólo se citen mayoritariamente dos frases: "prefiero ser un cyborg a ser una diosa. Pero todas las denuncias de Haraway sobre cómo afectan de manera distinta las nuevas tecnologías sobre la mujer, apenas son referenciadas. En este trabajo me he centrado en el manifiesto de Haraway para demostrar que propone algo más que ser un cyborg. Sin descuidar el espacio artístico del ciberarte, que tiene su propio lenguaje y su propia eficacia, es evidente que las ciberfeministas proponen una mayor y más amplia actuación política y social para combatir la secular cultura antropomórfica (Wilding, 1998. Reverter-Bañón, 2000. Haraway, 1991). Actuación que no se puede dejar en manos de la tecnología, como ente autónomo que nos vaya a salvar, pues, la tecnología son investigaciones, más o menos particularizadas, llevadas a cabo por gente. Y no podemos confiar en que los males antropocéntricos se arreglarán con las nuevas tecnologías, sólo porque éstas sean supuestamente femeninas, surgidas de la urdimbre de los telares, cuando la lanzadera es manejada con valores de género, siguiendo con la metáfora. Es evidente que las tecnologías llevan el peso de las ideas de aquellos que las soñaron.

\section{BIBLIOGRAFÍA}

BRAIDOTTI, R. (1996): Ciberfeminism with a Difference, en http://www.let.uu.nl/ Rosi. Braidotti/personal/

DA RIMINI, F. (1991): Cyberfeminist Manifesto for the 21st Century, en http://1x.sysx.org/ vnsmatrix.html

- (1996): Bitcht Mutant Manifesto, en http://lx.sysx.org/vnsmatrix.html

DAWKINS, R. (1990): ( $2^{\mathrm{a}}$ edición ) The Selfish Gene, Oxford, Oxford University Press.

DEMENT, L. (1995): Cyberflesh Girlsmonster, en http://www.lindadement.com/

GALlOWAY, A. (1998): A Report on Cyberfeminism. Sadie Plant relative to VNS Matriz, en http://switch.sjsu.edu/web/v4n1/alex.html 
GRUBINGER, E. (1995): Neztbikini, en http://www.thing.at/netzbikini/ (07/01/98)

HARAWAY, D. J. (1984): Ciencia, cyborgs y mujeres. La reinvención de la naturaleza, Madrid, Cátedra.

HARDING, S. (1996): Ciencia y feminismo, Madrid, Morata.

HAWTHORNE, S. y KLEIN, R. (ed.) (1999): CyberFeminism: Connectivity, Critique and Creativity, Melbourne, Spinifex Press.

KRIPTOPOLIS. (2001): Definiendo al ciberfeminismo, en http://www.creatividadfeminista.org/ KUNI, V. (1998): The Future is Femail. Some Thoughts on the Aestetics and Politics of Cyberfeminism, en http://www.obn.org/

MANN, S. y NIEDZVIECKI, H. (2002): Cyborg: Digital Destiny and Human Possibility in the Age of the Wearable Computer, Toronto, Anchor Canada.

OBN, (1997): 100 anti-thesis cyberfeminism is not..., en http://www.obn.org/ PATERSON, N. (1998): Stock Market Skirt and new directions, en http://www.vacuumwoman.com/

PLANT, S. (1997): Ceros + Unos. Mujeres digitales + la nueva tecnocultura, Barcelona, Destino.

REVERTER-BAÑÓN, S. (2000): Ciberfeminismo: entre la (u)topía y la (dis)topía, en http://www.creatividadfeminista.org/

TURKLE, S. (1997): La vida en la pantalla. La construcción de la identidad en la era de Internet, Barcelona, Paidos.

WILDING, F. (1998): Where is Feminism in Cyberfeminism?, en http://www.obn.org/

WILDING, F. \& CAE. (1998): Notes on the Political Condition of Cyberfeminism, en http://www.obn.org/ 